\title{
ANÁLISE DOS LIVROS DIDÁTICOS DE QUÍMICA DO PNLD 2015: TABELA PERIÓDICA
}

Fernanda Dias da Silva, Universidade Federal de Campina Grande (UFCG), soufernandadias@gmail.com

Saniel Ferreira, Universidade Federal de Campina Grande (UFCG), sanielferreira80@gmail.com

Luciano Leal de Morais Sales, Universidade Federal de Campina Grande (UFCG), luciano_sales@hotmail.com

PALAVRAS-CHAVE: Livro didático, Tabela Periódica, Abordagem contextual.

\section{INTRODUÇÃO}

O livro didático ainda hoje é o material mais utilizado pelo professor em suas aulas, seja como fonte de pesquisa bibliográfica, como fonte de consulta para aluno e professor, como proposta de exercícios ou até mesmo como único material didático utilizado em sala de aula (Cordeiro, 2013). A atual realidade educacional vai mais além, relegou ao professor um papel secundário em que sua ação na maioria das vezes é seguir um manual didático que lhe servirá de programa, de instrumento de planejamento, de livro de estudo e de caderno de atividades restando ao professor único e exclusivamente o livro didático e a tarefa de reproduzi-lo (Pretto, 1985). Verifica-se assim que o livro didático transformou-se de um dos recursos pedagógicos disponíveis em o único material didático utilizado, substituindo, às vezes, o próprio professor (Mohr, 2013).

O Programa Nacional do Livro Didático (PNLD) tem como principal objetivo a universalização de acesso dos materiais didáticos a alunos da Educação Básica, e devido a este fator, destaca-se no quadro de políticas públicas nacionais para a educação. Devido às proporções de investimento relacionadas ao PNLD, há uma preocupação crescente com a produção de materiais didáticos de qualidade, avaliando dentre diversos parâmetros a atualização de conceitos apresentados, a disposição e coerência dos textos, a utilização de figuras e gráficos como recursos e a organização visual do livro didático.

De acordo com as propostas inovadoras para o ensino de ciências, que demonstram preocupação com diferentes fatores, como a contextualização, justifica-se a importância da 
abordagem utilizada na produção literária adotada pelo PNLD. Portanto, este trabalho tem como objetivo analisar as diferentes abordagens contextuais apresentadas nos livros de Química do PNLD 2015, tendo como foco a análise do conteúdo Tabela Periódica presente nos livros didáticos do PNLD com base na matriz de referência do Exame Nacional do Ensino Médio.

\section{METODOLOGIA}

Para a realização deste trabalho foram selecionados os livros: Ser protagonisda Química de Murilo Tissoni Antunes e Patricia A. dos Santos; Química cidadã de Wildson Luiz Pereira dos Santos e Gerson de Sousa Mol; Química de Eduardo Fleury Montiner e Andréa Machado e Química sde Marta Reis, ambos do primeiro ano do ensino médio. Foram analisados os capitulos de Tabela Periódica dos mesmos através de uma planilha com os seguintes criterios: (1) imagens presentes no livro didático; (2) linguagem e rigor científico; (3) evolução histórica do conteúdo; (4) contextualização do conteúdo; (5) relacionamento do conteúdo com o desenvolvimento tecnológico; (6) aspectos inerentes aos exercícios e problemas que são disponibilizados (Brasil, 1994).

\section{DESCRIÇÕES, RESULTADOS, INTERPRETAÇÕES}

Quadro 1: Livros analisados

\begin{tabular}{|l|l|c|l|}
\hline \multicolumn{1}{|c|}{ LIVRO } & \multicolumn{1}{|c|}{ AUTORES } & \multicolumn{1}{c|}{ EDITORA } & \multicolumn{1}{|c|}{ VOLUME } \\
\hline QUÍMICA & $\begin{array}{l}\text { Martha Reis Marques da } \\
\text { Fonseca }\end{array}$ & ÁTICA & LD1 \\
\hline SER PROTAGONISTA & Murilo Tissoni Antunes & SM & LD3 \\
\hline QUÍMICA CIDADÃ & $\begin{array}{l}\text { Eliane Nilvana Ferreira } \\
\text { de Castro/Gentil de } \\
\text { Souza Silva/Gerson de } \\
\text { Souza Mól/Roseli }\end{array}$ & \multicolumn{1}{c|}{ AJS } & \\
& $\begin{array}{l}\text { Takako Matsunaga/ } \\
\text { Salvia Barbosa Farias/ } \\
\text { Sandra Maria de } \\
\text { Oliveira }\end{array}$ & & \\
& $\begin{array}{l}\text { Santos/Siland Meiry } \\
\text { França Dib/Wildson }\end{array}$ & & \\
\hline
\end{tabular}

Revista de Pesquisa Interdisciplinar, Cajazeiras, n. 2, suplementar, p. 216-222, set. de 2017. 


\begin{tabular}{|l|l|l|l|}
\hline & Luiz Pereira dos Santos & & \\
\hline QUÍMICA & $\begin{array}{l}\text { Andréa Horta } \\
\text { Machado/Eduardo } \\
\text { Fleury Mortiner }\end{array}$ & SCIPIONE & LD4 \\
& & & \\
\hline
\end{tabular}

Fonte: Guia do livro didático 2015

Quadro 2 - Mostra a análise dos livros do PNLD 2015.

\begin{tabular}{|c|c|c|c|c|}
\hline CRITÉRIOS/LIVRO & LD1 & LD2 & LD3 & LD4 \\
\hline Imagens no livro* & $\begin{array}{c}\text { Poucas ilustrações, } \\
\text { mas boa nitidez. } \\
\text { (27 imagens) }\end{array}$ & $\begin{array}{l}\text { Poucas ilustrações, } \\
\text { mas boa nitidez. } \\
\text { (07 imagens) }\end{array}$ & $\begin{array}{c}\text { Grande } \\
\text { quantidade de } \\
\text { imagens com } \\
\text { alto valor } \\
\text { informativo } \\
\text { (62 imagens) }\end{array}$ & $\begin{array}{c}\text { Grande } \\
\text { quantidade de } \\
\text { imagens com alto } \\
\text { valor } \\
\text { informativo. } \\
\text { (114 imagens) }\end{array}$ \\
\hline $\begin{array}{l}\text { Linguagem e rigor } \\
\text { científico }\end{array}$ & $\begin{array}{l}\text { Linguagem bem } \\
\text { acessível sem fugir } \\
\text { do rigor científico. }\end{array}$ & $\begin{array}{c}\text { Linguagem } \\
\text { acessível, mas } \\
\text { mantendo o rigor } \\
\text { cientifico. }\end{array}$ & $\begin{array}{c}\text { Excelente } \\
\text { linguagem, } \\
\text { associada ao } \\
\text { rigor cientifico e } \\
\text { a fatos do } \\
\text { cotidiano. }\end{array}$ & $\begin{array}{l}\text { Boa linguagem, } \\
\text { associada a fatos } \\
\text { do cotidiano, } \\
\text { porém pouco } \\
\text { rigor científico. }\end{array}$ \\
\hline $\begin{array}{l}\text { Evolução histórica do } \\
\text { conteúdo }\end{array}$ & $\begin{array}{c}\text { Ótimo } \\
\text { desenvolvimento } \\
\text { histórico dos } \\
\text { conceitos sempre } \\
\text { os relacionando } \\
\text { aos cientistas } \\
\text { responsáveis por } \\
\text { eles. }\end{array}$ & $\begin{array}{l}\text { Evolução dos } \\
\text { conteúdos } \\
\text { históricos em } \\
\text { relação aos } \\
\text { conceitos do tema } \\
\text { bastante } \\
\text { resumidos. }\end{array}$ & $\begin{array}{c}\text { Bom } \\
\text { desenvolvimento } \\
\text { histórico dos } \\
\text { conceitos e } \\
\text { cientistas } \\
\text { responsáveis por } \\
\text { eles. }\end{array}$ & $\begin{array}{l}\text { Boa evolução } \\
\text { histórica, } \\
\text { seguindo } \\
\text { adequadamente a } \\
\text { cronologia } \\
\text { histórica das } \\
\text { descobertas } \\
\text { cientificas. }\end{array}$ \\
\hline Contextualização & $\begin{array}{c}\text { Bastante } \\
\text { contextualizado e } \\
\text { relacionado com o } \\
\text { cotidiano dos } \\
\text { discentes. }\end{array}$ & $\begin{array}{l}\text { Conteúdo bem } \\
\text { contextualizado, } \\
\text { porém não há } \\
\text { associação com o } \\
\text { cotidiano. }\end{array}$ & $\begin{array}{c}\text { Bastante } \\
\text { contextualizado } \\
\text { e relacionado } \\
\text { com o cotidiano } \\
\text { dos discentes. }\end{array}$ & $\begin{array}{c}\text { Boa } \\
\text { contextualização, } \\
\text { relacionando o } \\
\text { conteúdo com } \\
\text { acontecimentos } \\
\text { do cotidiano. }\end{array}$ \\
\hline
\end{tabular}




\begin{tabular}{|c|c|c|c|c|}
\hline $\begin{array}{c}\text { Relacionamento com o } \\
\text { desenvolvimento } \\
\text { tecnológico }\end{array}$ & Não possui. & Não possui. & $\begin{array}{c}\text { Manifesta } \\
\text { afinidade com } \\
\text { recentes } \\
\text { descobertas } \\
\text { tecnológicas e } \\
\text { pesquisas acerca } \\
\text { do conteúdo. }\end{array}$ & $\begin{array}{c}\text { Ótima } \\
\text { abordagem } \\
\text { tecnológica } \\
\text { demonstrando a } \\
\text { influência e a } \\
\text { importância da } \\
\text { ciência na } \\
\text { sociedade. }\end{array}$ \\
\hline $\begin{array}{c}\text { Aspectos inerentes aos } \\
\text { exercícios }\end{array}$ & $\begin{array}{c}\text { Exercícios } \\
\text { contextualizados } \\
\text { que remetem a } \\
\text { conteúdos } \\
\text { anteriormente } \\
\text { estudados. }\end{array}$ & $\begin{array}{c}\text { Elevação no grau } \\
\text { de dificuldade e } \\
\text { contextualização } \\
\text { dos exercícios a } \\
\text { cada questão. }\end{array}$ & $\begin{array}{l}\text { Demonstra clara } \\
\text { deficiência } \\
\text { oferecendo } \\
\text { questões, sem } \\
\text { problematização } \\
\text { alguma. }\end{array}$ & $\begin{array}{c}\text { Exercício bem } \\
\text { contextualizado e } \\
\text { de acordo com o } \\
\text { conteúdo } \\
\text { apresentado. }\end{array}$ \\
\hline
\end{tabular}

Fonte: Windson Timóteo de Sousa

A partir das análises dos livros didáticos foi possível caracterizar através do Quadro 2:

Ao se deparar com o primeiro critério de análise, pode-se perceber que a utilização de imagens em livros didáticos complementando o aprendizado textual, independente da quantidade de imagens. As coleções que trouxeram uma grande quantidade de imagens com alto valor informativo foram a LD4 com 114 imagens e a LD3 com 62 imagens. Outro caso foi à coleção LD1 que trouxe 27 imagens, transmitiram bem o assunto ao aluno através delas. A coleção LD2 foi a menos ilustrada com 07 imagens, dificultando assim o entendimento do leitor.

Ao analisar a linguagem cientifica dos capítulos de Tabela Periódica pode-se perceber a preocupação dos autores dos livros LD1 e LD2 em manter uma linguagem acessível, porém sem fugir do rigor cientifico, mas ambas deixaram a desejar ao não associar sua linguagem a fatos do cotidiano dos discentes. A coleção LD3 destacou-se por possuir uma Excelente linguagem, associada ao rigor cientifico e a fatos do cotidiano dos discentes. Seguida do livro LD4 que apresentou uma linguagem bastante associada a fatos do cotidiano, mas com quase nenhum rigor científico.

Assim, analisando a evolução histórica contida nesses livros pode -se compreender que os livros LD1, LD3 e LD4, trazem um desenvolvimento histórico favorável a construção do 
conhecimento do conteúdo, seguindo adequadamente a cronologia histórica das descobertas cientificas e sempre relacionando-as aos cientistas responsáveis por eles. A coleção LD2 apresentou uma evolução dos conteúdos históricos em relação aos conceitos do tema bastante resumidos, sem uma definição concreta dos conceitos a serem trabalhados no decorrer do capítulo, fragilizando o processo de aprendizagem dos discentes.

Em relação à contextualização nas quatro obras analisadas, apenas as obras LD1, LD3 e LD4, relacionaram fatos do cotidiano com o contexto estudado buscando melhorar o ensino aprendizagem dos discentes, relacionando o conteúdo da tabela periódica com acontecimentos vividos por eles no dia-a-dia. A obra LD2 apresentou uma contextualização bastante resumida e não contemplou nenhuma relação com o cotidiano dos alunos, tornando-se muito deficiente nesta questão.

Com relação à abordagem metodológica de apresentação dos conteúdos, nota-se que o livro LD3 e o livro LD4 trouxeram vários conceitos que facilitam a compreensão do conteúdo, demonstrando afinidade com recentes descobertas tecnológicas e pesquisas acerca do conteúdo sua influência na ciência, sociedade entre outras. A coleção LD1 e LD2 não apresentarão abordagens metodológicas de seus conceitos, não possuindo nenhuma organização de conceitos e idéias dificultando o processo de ensino aprendizagem e dificultando a compreensão das mesmas.

Ao serem contemplados os exercícios apresentados em cada livro didático assim como afirma Otesbelgue (2013), o qual prediz que os exercícios têm papel fundamental na formação do aluno, pois pode forçar o mesmo a contextualizar mais, levando os discentes a pesquisar sobre o assunto estudado. Assim, pode-se constatar que as obras LD1, LD2 e LD4 trouxeram questões adequadas às necessidades dos alunos, Exercícios contextualizados que remetem a conteúdos apresentados anteriormente, com uma elevação no grau de dificuldade e contextualização dos exercícios a cada questão, visando prepara- lo para futuros processos seletivo. Na obra LD3, há uma grande quantidade dos exercícios, porém sua maioria é dada de uma forma bem direta, demonstrando clara deficiência em sua problematização.

\section{CONSIDERAÇÕES FINAIS}


Conclui-se que das quatros coleções escolhidas para serem usados no PNLD 2015, ao serem analisadas quanto aos critérios necessários para uma boa formação, As coleções LD3 e LD4 destacaram-se em relação as demais pelo fato de encaixaram-se em quase todos os critérios levantados para a analise, sendo consideradas, as obras mais completas para se trabalhar o conteúdo de Tabela Periódica. Porém em quase todas as obras pode-se constatar falhas em pelo menos um dos critérios analisados, podendo então comprometer o desempenho do discente em relação ao conteúdo Tabela Periódica.

\section{REFERÊNCIAS}

BRASIL, Ministério da Educação. Edital de convocação 01/2013 - CGPLI. Edital de Convocação para o processo de inscrição e avaliação de obras didáticas para o Programa Nacional do Livro Didático - PNLD 2015, 2013.

BRASIL. MEC. Definição de critérios para avaliação dos livros didáticos. Brasília, 1994.

CORDEIRO, Marinês D.; PEDUZZI, Luiz O.Q. Consequências das de contextualizações em um livro didático: uma análise do tema radioatividade. Revista Brasileira de Ensino de Física, v. 35, n. 3, p. 3602, 2013.

LUIZ, W.P.S; SOUZA, G.M. Química Cidadã: Vol.1. 2.ed, São Paulo: Editora AJS, 2013.

MOHR, Adriana. A Saúde na Escola: análise de livros didáticos de $1^{\mathrm{a}}$ a $4^{\mathrm{a}}$ séries. Cadernos de Pesquisa, n. 94, p. 50-57, 2013.

MORTMER, E.F; MACHADO, A.H; Química: Vol.1. 2.ed, São Paulo: editora scipione, 2013

PRETTO, Nelson L. A ciência, nos livros didáticos. 1985

REIS, MARTHA. Química: Vol.1. 1.ed, São Paulo: editora ática, 2013.

TISSONI, M. A; SANTOS, P. A. Ser Protagonista: Química: Revisão do ensino médio. Vol. Único. 1.ed, São Paulo: Edições SM, 2014. 
TIMOTEO; W. S. Trabalho de Conclusão de Curso: A RADIOATIVIDADE NO ENSINO

MÉDIO: análise de livros didáticos de Química do PNLD 2015. Universidade Federal de Campina Grande, 2016. 